1939 bis 1945 dreimal verwundet. Seit 1947 wirkte er an der Bundesanstalt für Forst- und Holzwirtschaft, Reinbek, sowie an der Universität Hamburg.

Von seinem fruchtbaren wissenschaftlichen Schaffen zeugen u. a. die Bücher:

Forstliche Zuwachs- und Errragskunde. Radebeul und Berlin, 1. Aufl. 1948; 2. Aufl. 1955.

Die Wälder der Erde. Berlin, Göttingen, Heidelberg 1957.

Weltforstwirtschaft und Deutschlands Forst- und Holzwirtschaft. Teil I: Tatsachen und Probleme einer Weltforstwirtschaft. München, Bonn, Wien 1961.

Er ist weiter Verfasser von 5 Broschüren, mehrerer für ausländische Regierungen erstatteter Gutachten sowie von über 100 Zeitschriftenaufsätzen. Er war Herausgeber der Schriftenreihe "Weltforstwirtschaft" und Mitherausgeber der "Forstlichen Umschau“. Ein ausführliches Schriftenverzeichnis enthält der im „Forstarchiv“ erscheinende Nachruf.

Mit Johannes WECK verläßt uns, viel zu früh, ein in der ganzen Welt bekannter Forstwissenschaftler, dessen Ruf sich nicht nur auf bedeutende wissenschaftliche Leistungen gründet, sondern auch auf seine erfolgreiche beratende Tätigkeit in vielen Ländern der Erde, so vor allem in Indonesien, Chile und im Sudan. Ausgedehnte und anstrengende Reisen führten ihn in alle Teile der Erde. Er war Mitglied in 40 nationalen und internationalen Organisationen. Zahlreiche Ehrungen wurden ihm zuteil.

Mit den Angehörigen, Mitarbeitern und zahlreichen Schülern trauert die forstliche Welt um den viel zu frühen Heimgang dieses hervorragenden Gelehrten.

E. ASSMANN

\title{
Deutscher Forstwirtschaftsrat
}

Als Nachfolger von Profesor Dr. J. Speer, der zwölf Jahre lang den Deutschen Wissenschaftsrat geleitet hatte, wurde bei der Mitgliederversammlung in Aachen Professor Dr. Dr. h. c. K. Mantel zum neuen Präsidenten gewählt.

\section{BUCHBESPRECHUNGEN}

Die Laubgehölze. Eine Dendrologie für die Praxis. Von Gerd Krüssmann, Dendrologe am Botanischen Garten in Dortmund-Brünninghausen. 3., völlig neubearb. Aufl. 397 S. mit 3321 Gehölzbeschreibungen und 150 z. T. ganzs. Abb. i. Text, Verlag Paul Parey, Berlin und Hamburg 1964, Gzln. 54,- DM.

Der bekannte Dortmunder Dendrologe, Verfasser der Bücher "Die Nadelgehölze“, "Handbuch der Laubgehölze“, "Die Baumschule“" und "Taschenbuch der Gehölzvermehrung" "hat das seit 6 Jahren vergriffene Werk "Die Laubgehölze" in dritter Auflage, 13 Jahre nach Erscheinen der zweiten Auflage, völlig neu bearbeitet. Das Buch, gewissermaßen das Gegenstück zu dem vorzüglichen Werk „Die Nadelgehölze“, behandelt Laubgehölze, die in Gärten, Parks und Baumschulen Deutschlands, Hollands, Belgiens, Nordfrankreichs, der Schweiz, Ósterreichs und der skandinavischen Länder anzutreffen sind. $\mathrm{Da}$ Laubgehölzarten, die nur botanisches, aber kein gärtnerisches Interesse besitzen, nicht mehr enthalten sind, konnte die Zahl der behandelten Arten von 5850 der 2. Auflage auf 3321 Arten und Formen reduziert werden. Diese sind jedoch sehr gründlich beschrieben, wobei durch Sterne und andere Signaturen der Gartenwert, Ansprüche an Belichtung und Boden sowie die Winterhärte gekennzeichnet werden. 